\title{
Low Powered Solar ECG with ZigBee Based Bio-Telemetry
}

\author{
Parin Dedhia ${ }^{1, *}$, Harsh Doshi ${ }^{2}$ and Mrunal Rane ${ }^{2}$ \\ ${ }^{1}$ Electrical and Computer Engineering, Cornell University, New York, USA \\ ${ }^{2}$ Biomedical Engineering, D.J. Sanghvi c.o.e., Mumbai, India
}

\begin{abstract}
The advent of modern age has shown a drastic shift in the way humans have worked leading into sedentary lifestyles. Change in dietary pattern where fresh food is replaced by processed and fast food along with the increase of stress has led to rise of cardio-vascular disease which is glaringly evident in developing countries. Especially, Asians are more prone to cardio-vascular diseases genetically. The ECG device is a diagnostic medical instrument which determines the electrical activity of the heart. The conventional ECG devices are powered by mains electricity, thus are not energy efficient. Transformers used make the device bulky and expensive. Optimum isolation amplifiers have to be incorporated in these devices for patient safety, adding to the cost and complex circuit. We have designed a high quality solar electrocardiograph that is extremely energy efficient, cost effective and works on alternate energy, making it a completely eco-friendly product.

Healthcare infrastructure is extremely weak in various developing countries of Asia, Africa and South America. Electricity is one of the major factor that drives the health care economy in these areas. Most of these areas lack basic electricity, thus have no access to good health care facilities. One of the most essential factors in developing a solar based ECG device is to give out an extremely energy efficient device yet excellent results and inexpensive in order to get net cost per test below $\$ 1$. Having eliminated conventional power supply, the electro cardiogram is free from line frequency noise of $50 / 60 \mathrm{~Hz}$, thus adding to excellent ECG quality. The device is incorporated with a traditional DC charging facility, thus can be charged with a normal cell phone charger in extreme case. The device is capable of acquiring ECG for more than 30 hours, at a sampling rate of $500 \mathrm{~Hz}$. The ECG can be wirelessly transmitted with the help of low power wireless ZigBee, thus allowing monitoring ECG in real time.
\end{abstract}

Keywords: Cost per test, ZigBee, energy efficient, eco-friendly.

\section{INTRODUCTION}

The cardiovascular crisis is glaringly evident in developing nations. While these nations are still trying to shake of diseases rooted in poverty, both the urban and rural areas are experiencing a mounting epidemic of cardiovascular (CV) disease, which was until recently considered a disease of the 'urban rich'. And unfortunately, the toll promises to grow largely because the risk factors for cardiovascular diseases are pervading in low income groups and because this population is still youthful [1]. The most important reason for this epidemic is related to the economic and cultural influences of globalization [2].

The resulting explosive and chaotic urbanization has come with profound lifestyle changes. Added to this conundrum is the rising consumption of tobacco. The outcome is a tragic to say the least, evident is the abysmal statistics.

In India about 50 percent of CVD-related deaths occur among people younger than 70 , compared with about 22 percent in the West [3]. While 80 percent of Indian villages have at least an electricity line, just $52.5 \%$ of rural households have access to electricity

*Address corresponding to this author at the Electrical and Computer Engineering, Cornell University, New York, USA; Tel: (+1) 607-379-9681; Fax: (9122) 67995453; E-mail: parin99@hotmail.com
[4]. In urban areas, the access to electricity is $93.1 \%$ in 2008. The overall electrification rate in India is $64.5 \%$ while $35.5 \%$ of the population still lives without access to electricity [4]. Looking at these fundamental issues with alarming statistics, it is essential to develop equipment which can monitor cardiac activity, with minimum dependency on line voltage and is inexpensive to aid the rural sectors.

Thus, it is utmost important to revive global healthcare system with health care devices which are inexpensive and energy efficient. The device should be capable of continuous monitoring for long hours. It should be designed using low power electronic components, yet very efficient in giving excellent results. The next generation devices must be driven by an alternate source of energy. They must be extremely portable and light in weight, allowing the clinician to carry along. Real time monitoring is very crucial and important feature for any medical device, allowing wirelessly transmitting of data to PC or cell phone in most secured mode, incorporated with digital data storage.

\section{SYSTEM DESCRIPTION}

Our aim was to design a low power electro cardiograph which is powered by solar cells, yet acquire and transmit excellent ECG waveform over large distance securely. 


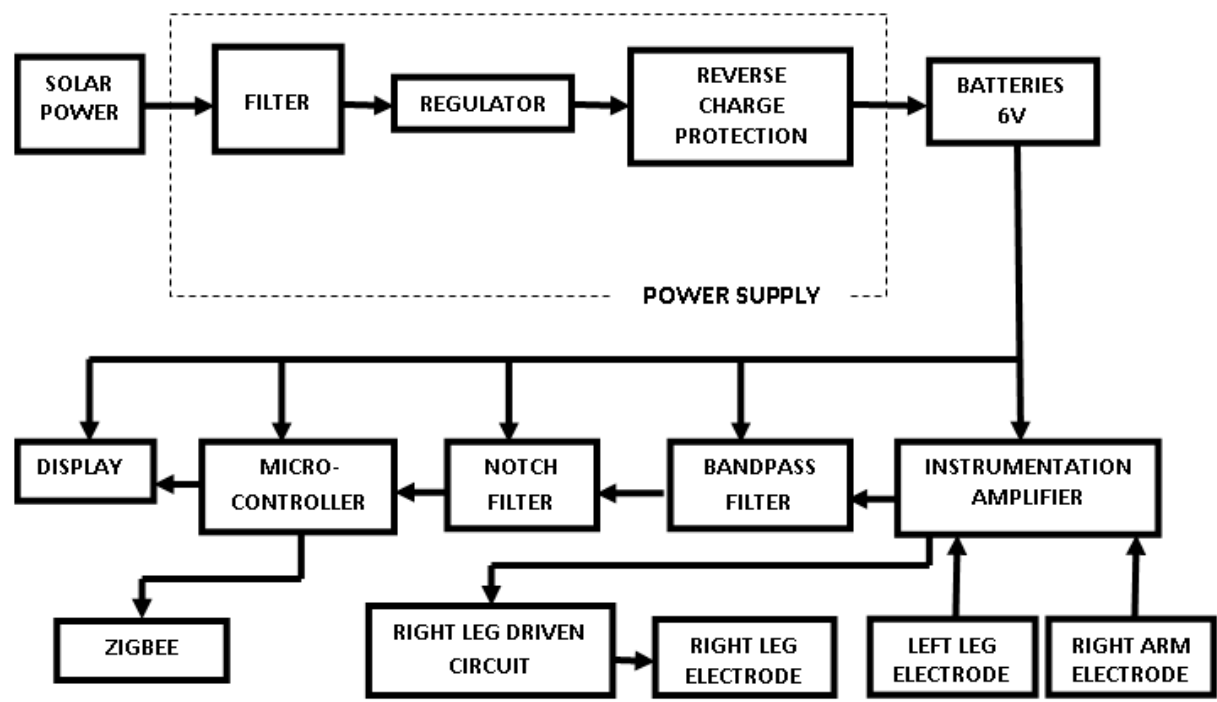

Figure 1: Patient acquisition and processing module.

\section{A. Hardware Description}

Figure 1 shows the block diagram of the device.

\section{i. Solar Power and Power Management System}

Solar Cells are arranged in series \& parallel combinations to give $6 \mathrm{~V}$ and 3 Watts giving about 500
$\mathrm{mA}$ of current in bright sun light. The DC output from the solar panel may get super imposed by white noise and various random frequencies, thus reducing the efficiency of the battery. Capacitive filters are incorporated to eliminate this undesirable noise. The output of the solar panel is regulated to 6.5 volts to safely charge the batteries. In low light and night

Table 1: Comparison of Different Rechargeable Batteries

\begin{tabular}{|c|c|c|}
\hline Battery Type & Self-Discharge Rate & Characteristics \\
\hline $\begin{array}{l}\text { Lithium-ion } \\
\quad \text { (Li) }\end{array}$ & $\begin{array}{l}\text { Does not hold charge well over long periods. } \\
\text { Loses } 8 \text { percent per month, much more in } \\
\text { warm temperatures [5]. }\end{array}$ & $\begin{array}{c}\text { No Memory Effect. } \\
\text { High current discharge and amperage. } \\
\text { Lithium in contact with water may explode. } \\
\text { Not Environment friendly. } \\
\text { Complex electronics required to curtail excessive } \\
\text { charging. } \\
\text { Expensive batteries. }\end{array}$ \\
\hline $\begin{array}{l}\text { Low-Self Discharge } \\
\text { Nickel-Metal Hydride } \\
\quad(\text { LSD NiMH) }\end{array}$ & $\begin{array}{l}\text { Holds charge well over long periods. } \\
\text { Loses } 15 \text { percent per year, very slightly more } \\
\text { in warm temperatures [5]. }\end{array}$ & $\begin{array}{l}\text { Works well in devices that require sudden high } \\
\text { amperage discharge, ideal for medical devices. } \\
\text { No memory effect \& Eco-friendly. } \\
\text { Safe to use. } \\
\text { Expensive batteries }\end{array}$ \\
\hline $\begin{array}{l}\text { Nickel-Cadmium } \\
\quad(\text { NiCad })\end{array}$ & $\begin{array}{c}\text { Loses } 1 \text { percent per day, slightly more in } \\
\text { warm temperatures [5]. }\end{array}$ & $\begin{array}{l}\text { Does not work well in devices that require sudden } \\
\text { high amperage discharges. } \\
\text { Suffers from memory effect (Cannot retain the } \\
\text { charge level after incomplete discharge). } \\
\text { Environmentally hazardous due to cadmium. } \\
\text { Inexpensive batteries }\end{array}$ \\
\hline Lead-acid & Loses $8-15 \%$ charge per month [5]. & $\begin{array}{l}\text { Low cost, spill resistant (Sealed batteries). } \\
\text { Limited low temperature performance. } \\
\text { Vented cells require maintenance. } \\
\text { Cells are relatively heavy. } \\
\text { Lead requires very complex disposal, else can prove } \\
\text { fatal to the environment. } \\
\text { Lead leakage adds to pollution. }\end{array}$ \\
\hline
\end{tabular}


conditions, the potential difference across the solar panel will be far less as compared to the battery, thus a leakage current will flow from the battery into the solar cells, damaging them over a period of time. In order to avoid such conditions, a reverse charge protection circuit has been made use of. Low self-discharge $\mathrm{NiMH}$ rechargeable batteries will in turn power the analog circuit, digital circuit and LCD display with 5 Volts.

Calculating charge time required:

For a fully discharged LSD-NiMH battery, an approximate charge time can be calculated using the following formula [4]:

Hours of Charge $=\frac{\text { Battery mAh Capacity }}{m \text { A charge rate }} \times 120 \%$

We conclude with the following graphical representation summarizing that low self-discharge Nickel metal hydride rechargeable batteries are ideal for our device.

From Figure 2, we can conclude that LSD-NiMH batteries have low self-discharge and can be used efficiently.

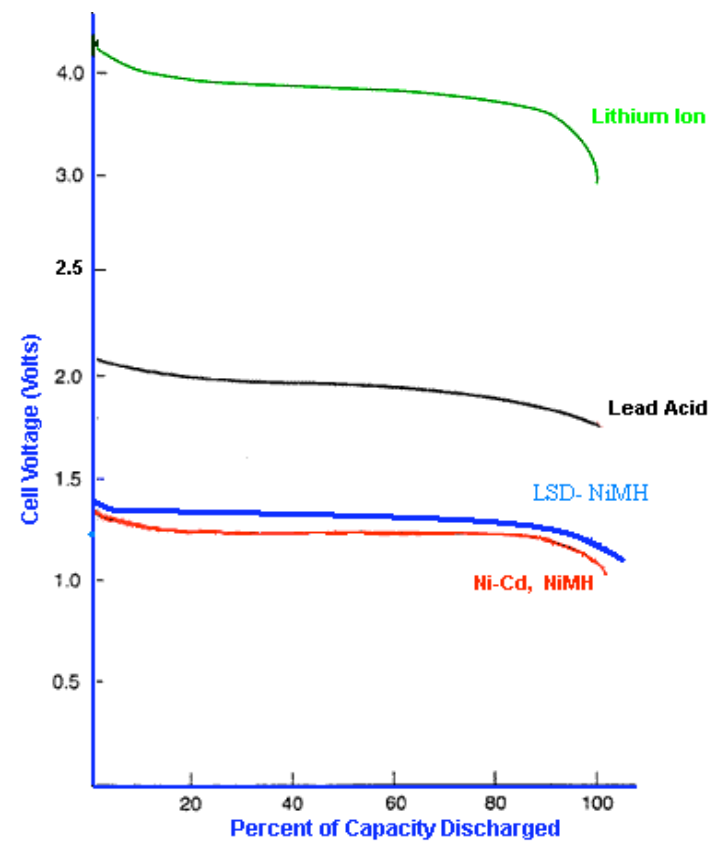

Figure 2: Performance evaluation of various batteries.

\section{ii. Sensors}

Four different coloured clamp electrodes have been used to acquire ECG in lead I, lead II and lead III configuration. Clamp electrodes are inexpensive and reusable thus can be easily used in areas where logistics is difficult. The acquired signal represents all the three Einthoven bipolar leads (Figure 3). By convention, lead II have the positive electrode on the left leg (LL), and the negative electrode on the right arm (RA), and therefore measure the potential difference by picking up the current flow from the positive left leg and negative right arm, via heart.

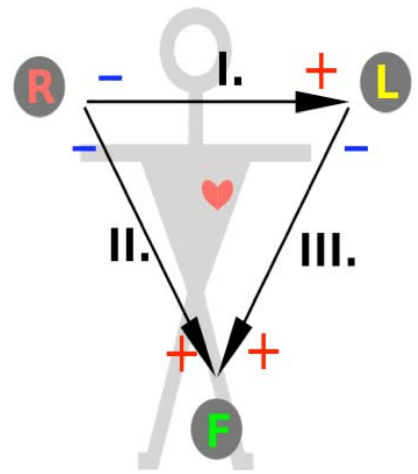

Figure 3: Einthoven Triangle [6].

\section{iii. Bio-Amplifier \& Driven Right Leg Circuit}

Biological signals are acquired from the body and have amplitude from a few micro volts to 1-2 milli volts. The acquired signal being very small in amplitude cannot be processed for further applications without amplification and filtering. Therefore an instrumentation amplifier with a gain of 1000 , very high input impedance of $10 \mathrm{G} \Omega$ and a CMRR greater than $110 \mathrm{~dB}$ is required. Very high CMRR of 110 decibels will reduce most of the noise from the desired signal. Very high input impedance allows the driving signal from not getting loaded and distorted. Instrumentation amplifier used also consumes very less power making the device energy efficient.

The patient's body tends to pick up the line frequency noise by acting as an antenna, thus disrupting the signal completely. A Driven Right Leg Circuit or "DRL" circuit is an electric circuit that is often added to biological signal amplifiers to reduce Common-mode interference. Right Leg Driver circuitry is used to eliminate interference noise by actively canceling the interference.

\section{iv. Signal Conditioning}

Acquisition of quality ECG data is critical in providing accurate and timely diagnosis and patient treatment.

Poor ECG quality can result in:

- The monitor's inability to recognize the R-wave, thus affecting arrhythmia analysis and the ability 

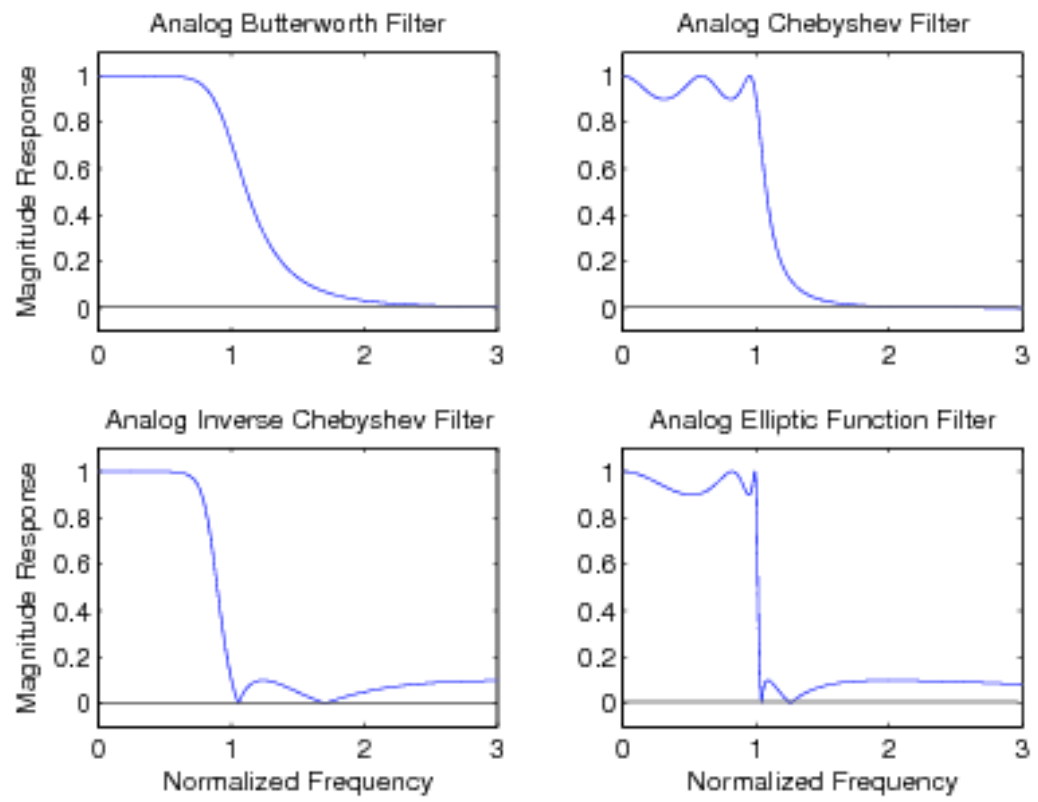

Figure 4: Comparison of Classical IIR Filter Types [7].

to perform procedures such as synchronized cardio version and transcutaneous pacing,

- $\quad$ False alarms and unnecessary troubleshooting, potentially delaying treatment.

Analog signal conditioning circuit is not as efficient as the digital signal conditioning circuit. The major disadvantage with the latter is it increases the cost of the whole device tremendously; therefore, we developed a very efficient analog filtering system to eliminate the noise, reaching about $90 \%$ of the efficiency of that of the digital one, and, bringing the cost down to one-fourth of that of digital.

Figure 4 shows the frequency response of different active filters. The Butterworth filter rolls off more slowly around the cutoff frequency than the Chebyshev filter or the Elliptic filter. The Butterworth filter has ripple free frequency response, giving it a flat pass band and making it ideal for medical applications.

Figure 5 shows PSPICE simulation of the frequency response of second order Butterworth band pass filter

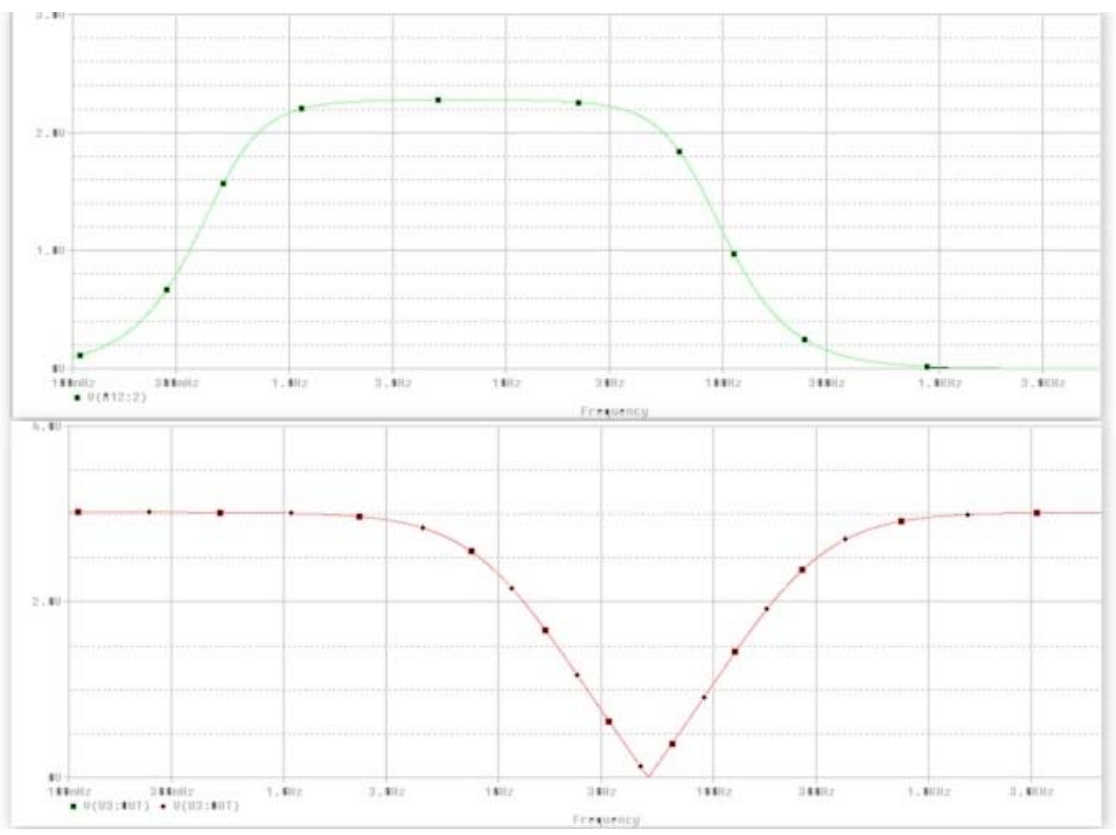

Figure 5: Response of designed active filters used in the ECG acquisition. 
and a notch filter $(50 \mathrm{~Hz})$. With the help of PSPICE simulations and experiments, we conclude that Second order Butterworth filter is ideal for our application.

\section{v. Signal Digitizing}

The output of the ECG is in analog form. In order to transmit, store and display, the analog signal needs to be converted into digital signal using an $A$ to $D$ convertor. An Arduino Uno with ATmega328 is used for the above applications. This device is low cost 8-bit Flash Microcontroller with 10-bit multi-channel Analog to Digital converter. According to the Nyquist criterion, the sampling frequency should be twice greater than the signal frequency. Thus, $500 \mathrm{~Hz}$ sample frequency is selected.

\section{vi. ZigBee for Bio-Telemetry}

ZigBee being the easiest and quickest mode of wireless communication these days has been chosen in our design over conventional thermal printer. Zigbee is the cheapest and most energy efficient wireless protocols amongst all. Thermal printing isn't highly reliable as the print fades off over a period and thermal printers are least energy efficient. Avoiding the use of papers as well as being a solar powered makes the device complete eco-friendly.

Thus the equipment requires ZigBee to transmit the digital data for its bio-telemetry application. The ZigBee module used was the XBee chip from Maxstream (Figure 6). The $2.4 \mathrm{GHz}$ band, in which ZigBee transceivers are most commonly deployed, uses the OQPSK (offset quadrature phase-shift keying) modulation stream.

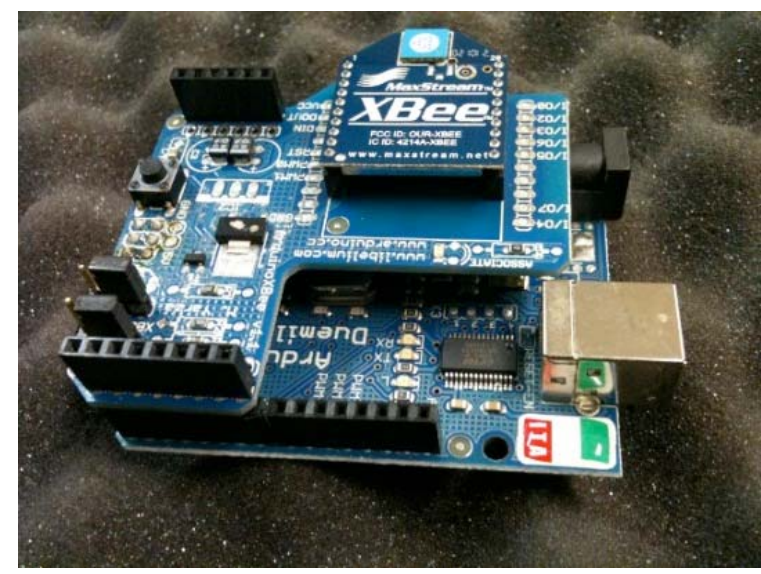

Figure 6: XBee ZigBee chip interfaced with Arduino.

\section{vii. Display on Graphic LCD}

The three leads ECG waveform is displayed on the $128 \times 64$ dots GLCD. The graphical LCD display is a memory mapped peripheral that permits menu-driven user interaction, warning messages, and real-time signal display [9]. The display that we used (LCD128G064E) has a $128 \times 64$ dot matrix in a $54 \mathrm{~mm} \times 50$ $\mathrm{mm}$ module [10]. The LCD controller and LED back light required $5 \mathrm{~V}$ for operation. The display draws $5 \mathrm{~mA}$ when it is on [10].

LCD-128G064E is inexpensive and consumes low power making it ideal for this system. Its compactness allows in designing a very portable device.

\section{viii. Digital Data Storage}

The digitized ECG signal can also be stored in the SD card using the Arduino microcontroller. Digital storage allows the data to be preserved for a very long time, without getting distorted.

\section{ix. Energy Efficiency and Power Consumption}

The device aimed to transform the healthcare in under developed areas needs to be very low on power consumption, in turn highly energy efficient.

Backlight LCD consumes good amount of power in any device. LCD-128G064E consumes $49.5 \mathrm{~mA}$ of current with maximum brightness [10]. Current consumption can easily be brought down by controlling the brightness using a potentiometer. Instrumentation amplifier is highly energy efficient consuming only $1.3 \mathrm{~mA}$ of current. Operational amplifiers used in the hardware consume not more than $1 \mathrm{~mA}$ of current. Atmega328 microcontroller consumes extremely less current in order of micro amperes and the ZigBee module consumes about $50 \mathrm{~mA}$ of current [8]. Considering total current consumption of $100 \mathrm{~mA}$ and charge capacity of LSD-NiMH batteries as $3500 \mathrm{~mA}$, a maximum resulting autonomy of 30 hours is achieved which can be increased with a potentiometer (controlling brightness) and higher charge capacity batteries.

\section{x. Development Environment}

The specification, design and implementation of the acquisition module were carried out using $O R C A D_{\circledast}$, Proteus Professional V7.6®. ORCAD software was used to create PSPICE simulations of frequency response of filters. Proteus Professional was used to design PCB layout for the hardware design.

\section{CHALLENGES}

The most crucial section of this research project was to design a very efficient hardware electronic 
circuit in order to achieve an undistorted ECG waveform. Conventional ECG devices are incorporated with a digital signal processor to eliminate the interference and white noise. Digital signal processors are very expensive and power consuming, but give out excellent results. In order to make the device cost effective and energy efficient, a very efficient analog circuit is required to filter out the interferences completely. We invested a lot of time in developing such hardware for the device, experimenting with various types of active filters, constantly varying the order of the filters, and, incorporating very high precision, yet ultra-low power electronic components.

Second biggest challenge was the management of solar power and battery charge. In order to have a portable device, the solar panel could not be very large. Smaller solar panels give out lesser output power, thus not sufficient to drive the device for long hours. We had to figure out an optimum solution, taking into consideration the design size limitations and power requirement. We had to consider various parameters of battery safety, like; optimum and constant charging current for maintaining the battery's charge-discharge cycle, as solar charging is very random, varying tremendously with the varying sun light. In order to protect the solar cells during low light conditions, a reverse charge protection circuit had to be incorporated. Incorporating a battery charging backup option was vital, allowing immediately charging of the device in extreme condition.

As the design had to consume very less power, research on various electronic components was vast, figuring out the best solution in terms of efficiency in output as well as energy. Programming the graphics LCD and wirelessly transmission of data was a tough task, considering no loss of data in any case and with an amazing output result. Thus, having got waveform display, wirelessly transmission and digital data storage in the system, power management was one of the most crucial sections of the device. We could achieve about 30 hours of continuous monitoring of high quality ECG, overcoming all the above challenges and coming out with an extremely cost effective device.

\section{RESULTS}

Figure 7 shows an ECG waveform distorted by high level of line frequency noise $(50 \mathrm{~Hz} / 60 \mathrm{~Hz})$. The required waveform is superimposed by the unwanted line frequency noise, corrupting the crucial data from the signal. Stage 1 of the project involved designing the circuit without high precision filters and conventional power supply system with a transformer.

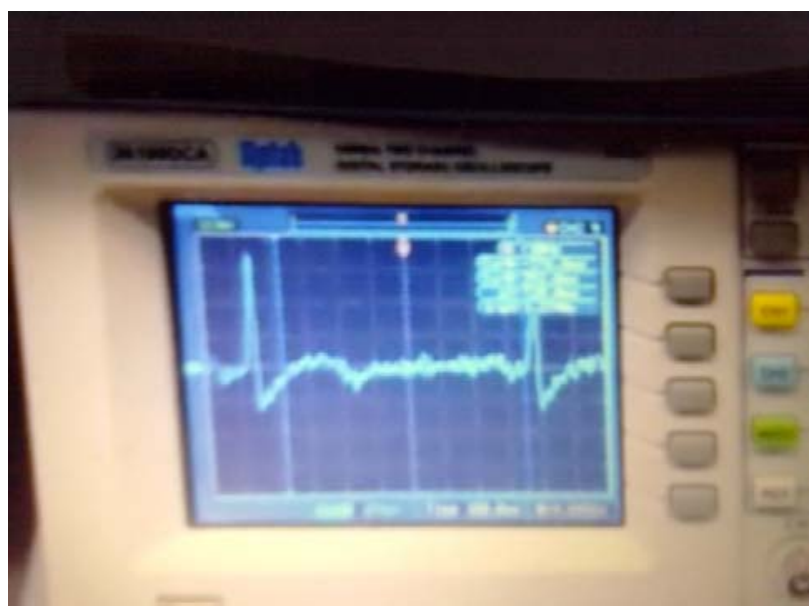

Figure 7: Distorted ECG waveform with high level noise (Stage 1) [11].

Figure 8 shows an ECG waveform distorted by medium level noise, partially corrupting the important data in the waveform. Stage 2 of the project involved high precision filters but was with conventional power supply system. Thus, high precision integrated circuits could eliminate interference to a certain level.

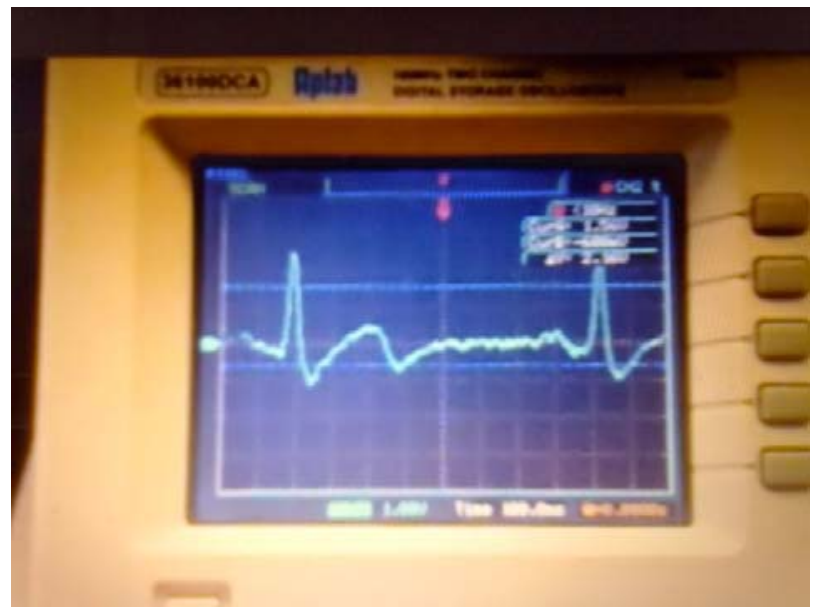

Figure 8: Medium level noise superimposed on ECG (Stage 2) [11].

Figure 9 shows an undistorted noise-free ECG waveform which can be used for detection of cardiovascular diseases. Final stage was achieved using high precision analog filters and driven by solar cells. The line frequency noise superimposed on the ECG signal degrades the quality of the signal, wherein the $P, Q, R$, $S$ and $T$ wave cannot be examined effectively (Figure 7). Use of effective and very high precision analog filters and elimination of mains power supply helped in achieving high quality ECG. The displayed output is an Amplitude v/s Time ECG waveform. 


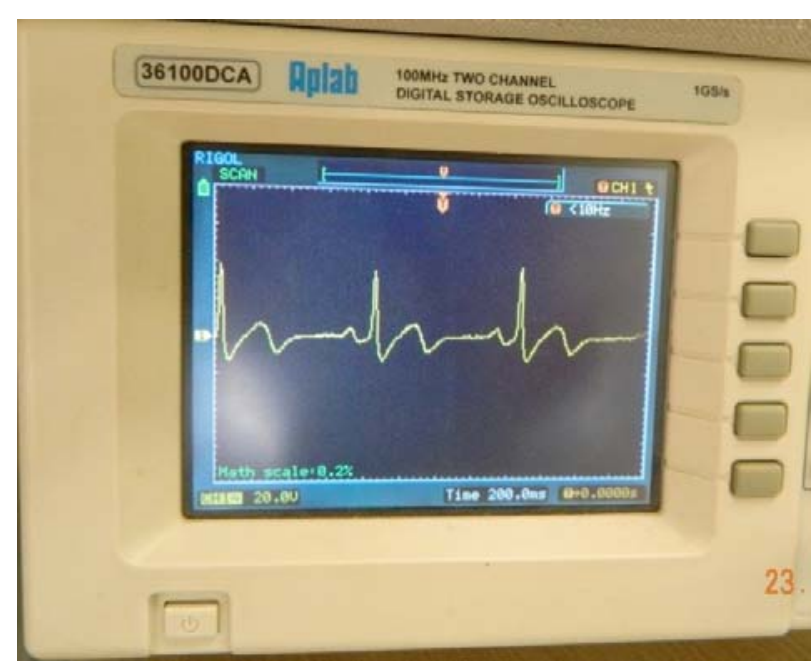

Figure 9: Noise-free and undistorted ECG (Final stage of the project).

\section{POTENTIAL IMPACT}

Conventional ECG device uses complex and expensive digital signal processors to achieve high quality ECG. These digital signal processors are very expensive, thus making the device very expensive and bulky. Ultimately, this affects the masses with very high cost per test, going up to $\$ 1000$ in certain areas. Conventional devices are electricity dependent and digital signal processors sink in a lot of power, making the device energy inefficient. Energy efficient and alternate energy products are required to sustain the energy crisis. With our significant efforts, we could design a competent hardware to filter out all the interferences and white noise completely. We were successful enough in wirelessly transmitting the data along with displaying it on the graphics LCD. The device consumes very less power, thus allowing a continuous monitoring for about 30 hours on a single charge. Being a solar powered device, it can be used practically in every area, be it multi-specialty hospital or a rural clinic. It could even be carried to distant location for monthly checkups by the clinician. The device is highly competent and is developed under $\$ 150$, significantly decreasing cost per test to less than $\$ 1$.

\section{CONCLUSIONS}

On comparing Figures 7, 8 and 9, it can easily be concluded that a noise-free and undistorted ECG is achieved. The quality of the ECG waveform is not compromised by making the device inexpensive and solar powered. Conducting clinical trials on 15 cardiac patients by the cardio surgeon, it was proved that this device is efficient in arrhythmia detection.

The device is designed using inexpensive components viz. (Batteries, Solar cells, ECG electrodes, ICs and GLCD) without affecting the quality of the ECG. The project was designed and implemented in $\$ 150$, making it highly inexpensive and ideal for under developed and developing nations.

\section{ACKNOWLEDGEMENT}

Dr. Akshay Kumar has been helping us out with the clinical trials of the device. Saloni Vora and Aashumi Vora have been helping us out with the graphics. We acknowledge them for their kind support.

\section{REFERENCES}

[1] Pamnani D. Express Pharma-Fortnightly, insight for pharma professionals. 2009 January; 16-31. Available: http://www.expresspharmaonline.com/20090131/research01. shtml

[2] Mayor S. Cardiovascular disease threatens developing economies. BMJ [2004; 328:1032:3]. 2004, April 29; 328 doi: 10.1136/bmj.328.7447.1032-b. Available from: http://www.bmj.com/content/328/7447/1032.3

[3] India Core, Information on Indian Infrastructure \& Core Sectors, 2010, August 2010. Available from: www.indiacore.com/

[4] Leeder S, Raymond S, Greenberg H, Liu H, Esson K. A Race against Time: The Challenge of Cardiovascular Disease in Developing Economies - University of Columbia. 2004, April 26. Available from: http://www.earth.columbia.edu/news/2004/story04-06b04.html

[5] National Institute of Justice, New technology batteries guide, NIJ guide 200-98. Available from: https://www.ncjrs.gov/pdffiles/172868.pdf

[6] Levine E. Electrocardiography. 2011, August 10. Available from: http://emedicine.medscape.com/article/1894014overview.

[7] Burrus S. Design of Infinite Impulse Response (IIR) Filters by Frequency Transformations. 2008, November. Available from: http://cnx.org/content/m16909/latest/.

[8] Atmel, Atmega328P datasheet, United States. Available from: www.atmel.com/lmages/doc8161.pdf

[9] Segura-Juárez J, Cuesta-Frau D, Samblas-Pena L, Aboy M. A Microcontroller-Based Portable Electrocardiograph Recorder. IEEE Transactions on Biomedical Engineering 1686 - 1690. Polytech. Univ. of Valencia, Alcoi, Spain, 2004.

[10] Vishay, LCD-128G064E data sheet, Europe. Available from: http://www.vishay.com/

[11] Dedhia P, Doshi H, Ahuja G, Rane M. Low cost solar ECG with Bluetooth transmitter. Proceedings of IEEE International Conference on Biomedical Engineering (ICoBE-2012). 419 423. Penang, Malaysia, 2012. 